\title{
LEFT PARADUODENAL HERNIA- A CASE REPORT
}

\author{
Suba Ananthi Kumarasamy1, Bijun Sai Kannadath², Sandosh Soundamourthy³, Aruna Subramanian4, Brinda Ravichandran ${ }^{5}$
}

${ }^{1}$ Associate Professor, Department of Anatomy, Indira Gandhi Medical College and Research Institute, Puducherry.

${ }^{2}$ Graduate Research Assistant, Division of Gastroenterology, Hepatology and Nutrition, UTHealth, McGovern Medical School, Houston, Texas.

${ }^{3}$ Assistant Surgeon, Government Primary Health Centre, Mathianallur, Pudukottai, Tamilnadu.

${ }^{4}$ Professor, Department of Anatomy, Indira Gandhi Medical College and Research Institute, Puducherry.

${ }^{5}$ CRRI, IGMC and RI.

HOW TO CITE THIS ARTICLE: Kumarasamy SA, Kannadath BS, Soundamourthy S, et al. Left paraduodenal hernia- a case report. J. Evolution Med. Dent. Sci. 2018;7(17):2170-2171, DOI: 10.14260/jemds/2018/487

\section{PRESENTATION OF CASE}

During routine abdominal dissection of a 45 -year-old male cadaver, upon entering the peritoneal cavity, a left Paraduodenal Hernia (PDH) was observed. The sac contained the first few centimetres of the jejunum. The neck of the sac was to the left of duodenojejunal flexure. The mouth of the sac opened to the right. Inferior mesenteric vein with the ascending branch of the left colic artery was close to the mouth of the sac. The artery was first lying lateral and then crossed anterior to the vein.

Paraduodenal hernia is a type of congenital internal hernia, which occurs due to malrotation of midgut to form a potential space through which loops of small intestine invaginate. It can be present on either side of the mesenteric attachment of the small intestine. Left sided hernias are 3 to 5 times commoner than right sided ones. During dissection of a 45-year-old male cadaver, left paraduodenal hernia was observed with contents being first few centimetres of the jejunum into the fossa of Landzert. Inferior mesenteric vein with the ascending branch of left colic artery was lying close to the mouth of the sac. In strangulation of the left paraduodenal hernia to widen the mouth of the sac, care must be taken not to injure the inferior mesenteric vein and branch of left colic artery. Paraduodenal hernia is often missed and found incidentally on laparotomy or autopsy.

\section{CLINICAL DIAGNOSIS}

PDH is usually asymptomatic, hence commonly discovered incidentally at the time of laparotomy or autopsy. When symptomatic, the presentation occurs between the 4 th and 5 th decades of life. The common presentations are long history of recurrent abdominal pain, nausea and vomiting. The pain is exacerbated by eating and postural changes, but relieved by lying supine. ${ }^{1}$ PDH can also present as acute small bowel obstruction. Physical examination may reveal tenderness, distension and in rare cases a palpable mass. Computed tomography (CT) is the investigation of choice for the diagnosis of PDH.2

'Financial or Other Competing Interest': None.

Submission 05-01-2018, Peer Review 06-04-2018,

Acceptance 12-04-2018, Published 23-04-2018.

Corresponding Author:

Dr. Suba Ananthi Kumarasamy,

Associate Professor,

Department of Anatomy,

Indira Gandhi Medical College and Research Institute,

Kathirkamam-605009, Puducherry.

E-mail: subasara@yahoo.com

DOI: $10.14260 /$ jemds $/ 2018 / 487$

\section{(c) $(1) \subseteq$}

\section{DISCUSSION}

PDH was first described by Neubaur in 1786 during an autopsy. ${ }^{3}$ A theory for the origin of PDH was first put forth by Andrews in 1923, who proposed that PDH was the result of a congenital anomaly in the development of peritoneum. ${ }^{1}$ In the 5th week of embryonic development, an elongating midgut herniates into the umbilical cord. The herniated midgut then undergoes a counter-clockwise rotation of $90^{\circ}$ around the artery of midgut, superior mesenteric artery (SMA). Following this, the pre-arterial limb now lies on the left side of the artery. By the $10^{\text {th }}$ week, the herniated midgut migrated back to within the abdominal cavity with prearterial limb initially followed by post-arterial limb. After the migration, the intestinal loop undergoes $180^{\circ}$ counter clockwise rotation getting the pre-arterial limb to lie left to SMA and the post-arterial limb superior and right to the SMA. Following this the mesocolon fuses with the peritoneum. When there occurs a failure in fusion, a potential space is created behind the descending mesocolon called as the fossa of Landzert. Invagination of small intestine into this fossa leads to left PDH.4

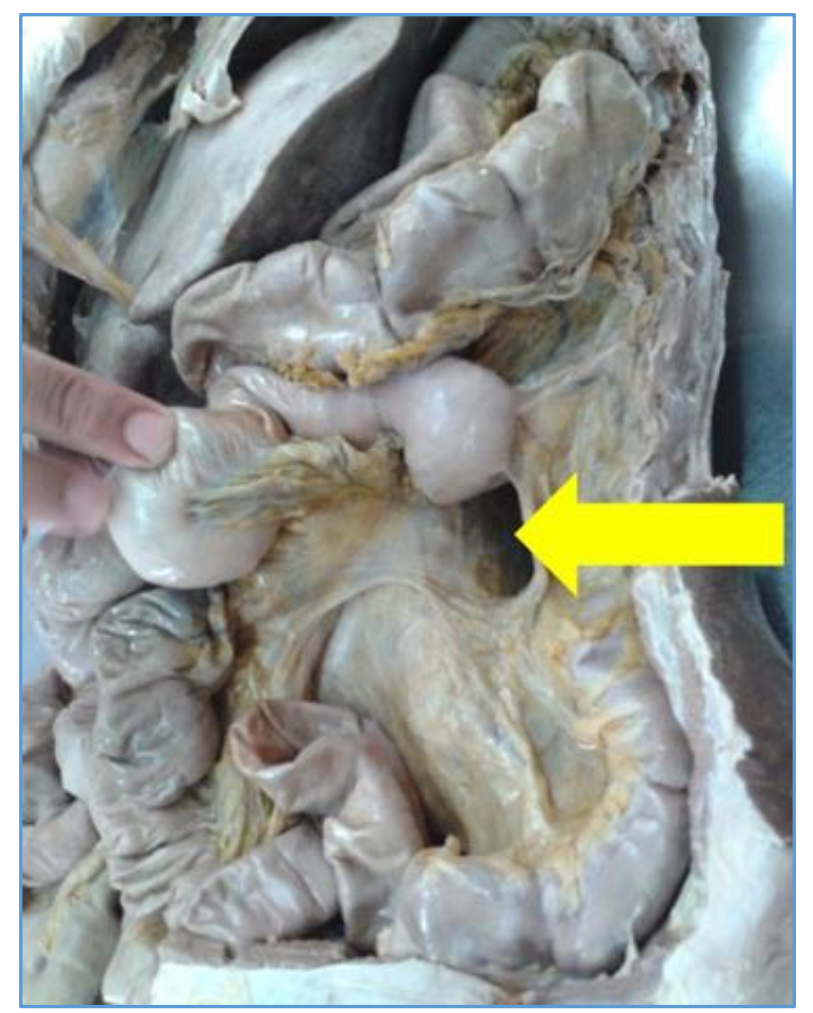

Figure 1. Yellow Arrow showing the Left Paraduodenal Hernia, Neck of the Sac lying to the Left of Duodenojejunal Flexure 


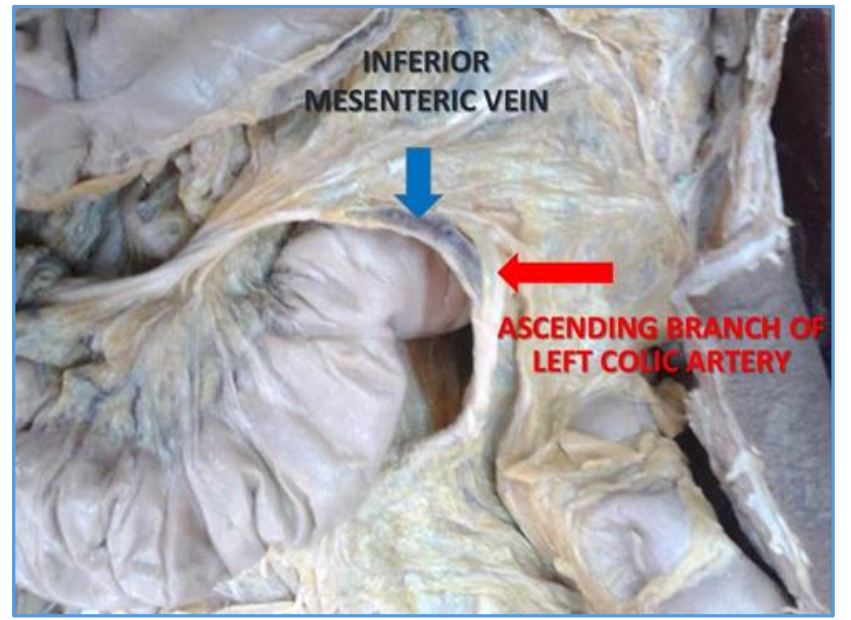

Figure 2. Blue Arrow showing the Inferior Mesenteric Vein and Red Arrow showing the Ascending Branch of the Left Colic Artery lying close to the Mouth of the Sac

\section{DISCUSSION OF MANAGEMENT}

Manual reduction of the hernia contents followed by repair of the defect is the treatment for left PDH. When manual reduction is technically difficult due to its bulky size or adhesions within the sac, an incision can be made in the avascular portion of the hernial sac to the right of the inferior mesenteric vessels to enlarge the opening. Since the Inferior Mesenteric Vein lies in the mouth of the sac, care should be taken not to injure the blood vessels.

\section{CONCLUSION}

$\mathrm{PDH}$ also known as paramesocolic hernia is the most frequent type of congenital internal hernia. PDH can be right or left according to the anatomical site of the hernia orifice. Left $\mathrm{PDH}$ is the most common type, which accounts for $75 \%$ of PDH with a male-to-female ratio of 3: $1 .{ }^{5}$ Clinical diagnosis of left PDH is challenging since symptoms are non-specific when present. Therefore, a timely and correct diagnosis with a rapid diagnostic tool is mandatory. During surgery, the relation of the inferior mesenteric vein with the branch of left colic artery to the hernia sac should be kept in mind. Since $\mathrm{PDH}$ is rarely reported by the anatomists, we report the case of left PDH from the Department of Anatomy.

\section{REFERENCES}

[1] Jamal MK, De Maria EJ. Internal hernias-congenital and acquired. In: Charles JY, eds. Shackelfold's surgery of the alimentary tract. $6^{\text {th }}$ edn. Vol I. Philadelphia, PA: Saunders 2007: p. 1120-3.

[2] Martin LC, Merkle EM, Thompson WM. Review of internal hernias: radiographic and clinical findings. Am J Roentgenol 2006;186(3):703-17.

[3] Bell-Thomson J, Vieta JO, Yiavasis AA. Paraduodenal hernias. Am J Gastroenterol 1977;68(3):254-9.

[4] Hirasaki S, Koide N, Shima Y, et al. Unusual variant of left paraduodenal hernia herniated into the mesocolic fossa leading to jejunal strangulation. J Gastroenterol 1998;33(5):734-8.

[5] Berardi RS. Paraduodenal hernias. Surg Gynecol Obstet 1981;152(1):99-110. 